\title{
Communication
}

\section{General Resilience to Cope with Extreme Events}

Stephen R. Carpenter ${ }^{1, *}$, Kenneth J. Arrow ${ }^{2}$, Scott Barrett ${ }^{3}$, Reinette Biggs ${ }^{4}$, William A. Brock ${ }^{5}$, Anne-Sophie Crépin ${ }^{4,6}$, Gustav Engström ${ }^{4,6}$, Carl Folke ${ }^{4,6}$, Terry P. Hughes ${ }^{7}$, Nils Kautsky ${ }^{8}$, Chuan-Zhong Li ${ }^{9}$, Geoffrey McCarney ${ }^{3}$, Kyle Meng ${ }^{3}$, Karl-Göran Mäler ${ }^{6}$, Stephen Polasky ${ }^{10}$, Marten Scheffer ${ }^{11}$, Jason Shogren ${ }^{12}$, Thomas Sterner ${ }^{13}$, Jeffrey R. Vincent ${ }^{14}$, Brian Walker ${ }^{4,15}$, Anastasios Xepapadeas ${ }^{16}$ and Aart de Zeeuw ${ }^{6,17}$

1 Center for Limnology, University of Wisconsin, Madison, Wisconsin 53706, USA

2 Department of Economics, Stanford University, Stanford, CA 94305, USA;

E-Mail: arrow@stanford.edu (K.J.A.)

3 School of International and Public Affairs/The Earth Institute, Columbia University, New York, NY 10027, USA; E-Mails: sb3116@columbia.edu (S.B.); grm2119@columbia.edu (G.M.); km2455@columbia.edu (K.M.)

4 Stockholm Resilience Centre, Stockholm University, 10691 Stockholm, Sweden; E-Mails: oonsie.biggs@stockholmresilience.su.se (R.B.); asc@beijer.kva.se (A.-S.C.); gustav.engstrom@beijer.kva.se (G.E.); carl.folke@beijer.kva.se (C.F.); Brian.Walker@csiro.au (B.W.)

5 Department of Economics, University of Wisconsin, Madison, WI 53706, USA; E-Mail:wbrock@ssc.wisc.edu (W.A.B.)

6 The Beijer Institute of Ecological Economics, The Royal Swedish Academy of Sciences, Box 50005, 10405 Stockholm, Sweden; E-Mails: Karl@beijer.kva.se (K.-G.M.); A.J.deZeeuw@uvt.nl (A.Z.)

7 ARC Centre of Excellence for Coral Reef Studies, James Cook University, Townsville, Queensland 4811, Australia; E-Mail: terry.hughes@jcu.edu.au (T.P.H.)

8 Department of Systems Ecology, Stockholm University, 10691 Stockholm, Sweden; E-Mail: NILS@ecology.su.se (N.K.)

9 Department of Economics, Uppsala University, Box 513, 751-20 Uppsala, Sweden; E-Mail: chuanzhong.li@nek.uu.se (C.-Z.L.)

10 Department of Applied Economics, University of Minnesota, 1994 Buford Avenue, St. Paul, MN 55108, USA; E-Mail: polasky@umn.edu (S.P.)

11 Department of Environmental Sciences, Wageningen University, PO Box 8080, 6700 DD, Wageningen, The Netherlands; E-Mail: Marten.Scheffer@wur.nl (M.S.) 
12 Department of Economics and Finance, University of Wyoming, Laramie, WY 82071, USA; E-Mail: JRamses@uwyo.edu (J.S.)

13 Environmental Defense Fund, New York, NY 10010, USA; E-Mail: Thomas.Sterner@economics.gu.se (T.S.)

14 Nicholas School of the Environment, Duke University, Box 90328, Durham, NC 27708, USA; E-Mail: jrv6@duke.edu (J.R.V.)

15 CSIRO Sustainable Ecosystems, GPO Box 284, Canberra, ACT 2601, Australia

16 Athens University of Economics and Business, 76 Patission Street, 10434 Athens, Greece; E-Mail: xepapad@aueb.gr (A.X.)

17 Department of Economics and CentER, Tilburg University, PO Box 90153, 5000 LE Tilburg, The Netherlands

* Author to whom correspondence should be addressed; E-Mail: srcarpen@wisc.edu; Tel.: +1-608-262-3014; Fax: +1-608-265-2340.

Received: 5 October 2012; in revised form: 12 November 2012 / Accepted: 14 November 2012 / Published: 28 November 2012

\begin{abstract}
Resilience to specified kinds of disasters is an active area of research and practice. However, rare or unprecedented disturbances that are unusually intense or extensive require a more broad-spectrum type of resilience. General resilience is the capacity of social-ecological systems to adapt or transform in response to unfamiliar, unexpected and extreme shocks. Conditions that enable general resilience include diversity, modularity, openness, reserves, feedbacks, nestedness, monitoring, leadership, and trust. Processes for building general resilience are an emerging and crucially important area of research.
\end{abstract}

Keywords: extreme events; general resilience; polycentric governance; resilience; social-ecological system

\title{
1. Introduction
}

Extreme events sometimes have long-lasting effects on social-ecological systems. Examples include storms such as Hurricane Katrina, wildfires like those in eastern Australia in 2009 or western North America in 2012, deep droughts such as the North American dust bowl, and the earthquake and tsunami that triggered the Fukushima disaster. Each of these events caused extensive losses and evoked searching reassessments of policies and practices for managing social-ecological systems.

Resilience, in the context of environmental management and sustainability, is the capacity of a social-ecological system to absorb disturbance, reorganize, and thereby retain essential functions, structures and feedbacks [1]. A rich and growing literature addresses specified resilience, the resilience 
of a particular aspect of a social-ecological system to a particular kind of disturbance [2]. For example, management of catchments in Australia seeks to avoid a water-table threshold that salinizes the soil and thereby destroys the fertility of agricultural land [1]. Vulnerability is a related concept that considers the stresses that lead to threshold changes in social-ecological systems. More specifically, "vulnerability is the state of susceptibility to harm from exposure to stresses associated with environmental and social change and from the absence of capacity to adapt" $[2,3]$.

For well-characterized shocks, there is often a good deal of information that is relevant to specified resilience. Risk analyses for large storms, earthquakes, floods, fires and other kinds of disturbance regimes are informed by existing knowledge. Even though each event is random, similar events have been seen before, and experience provides a basis for building specified resilience. For rather well-characterized hazards, The World Economic Forum [4] identifies several strategies that build specified resilience. These include monitoring hazards and communicating risk (through early warning systems, for example), social-physical strengthening (such as protection of power, water and sanitation plants, diversification of supply chains, and establishment of ecological buffers), sharing of financial risk (using insurance as well as instruments such as weather derivatives or catastrophe bonds), and disaster preparedness (e.g. training, or establishing reserves of pharmaceuticals). Numerous case studies provide practical information for building specified resilience to particular shocks $[1,5]$.

Other large-consequence events are outside the scope of experience. For example, no one foresaw that changes in animal feeding practices would lead to emergence of bovine spongiform encephalitis or mad cow disease [6]. In another recent case, the Honshu earthquake of 2011 was unusually powerful. It triggered a tsunami of $14 \mathrm{~m}$ that breached seawalls designed for the expected maximum wave height of $5.7 \mathrm{~m}$. The tsunami damaged nuclear power stations by shutting down back up diesel generators which were situated on the assumption that the sea walls would hold [7]. Extreme events that are unusually intense or extensive require a more all-purpose kind of resilience. General resilience is the capacity to absorb shocks of all kinds, including novel and unforeseen ones. The challenge of building resilience to unknown disturbances is far more difficult than planning for known types of disturbance, and like any management strategy it has a cost [1]. In this article, we discuss some approaches for building general resilience of social-ecological systems. We begin by discussing perceptions of extreme events that increase the need for general resilience. Next we summarize nine elements of general resilience based on the literature. We conclude by discussing some of the problems of implementing general resilience.

\section{Data and Perceptions about Record-Breaking Events}

Extreme events are challenging because the probabilities are hard to measure and because decisions about rare events with important consequences pose special challenges. Profound uncertainty makes rational responses difficult, and makes it easier for irrational approaches to take hold.

Extreme events are not only uncertain, but the measure of uncertainty (e.g. the tail of the probability distributions) also is itself uncertain. In some cases probabilities may be fundamentally unknowable, due to the complex interactions between human and environmental systems. The probability is obviously unknown for completely new events, such as the emergence of a particular new disease. However, probabilities may be poorly known even for events that have occurred only occasionally in 
the past. In the tails of probability distributions, observations are rare and therefore data are sparse for fitting models. As a consequence, trends in extreme events are hard to discern. For example, large data sets and extensive analysis are needed to establish trends in extreme rainfall events, flood damages or sizes of forest fires [8-12]. Where limited data make it hard to measure the probability of a certain kind of extreme event, assessing a trend in that probability is even more difficult.

Some classes of extreme events, such as flood damages, earthquake magnitudes, and wildfire sizes, have 'fat-tailed' probability distributions. In fat-tailed distributions the probability densities of extreme events are much larger than in more familiar distributions such as the normal distribution $[13,14]$. In these cases it is highly misleading to estimate the magnitude of the next record-breaking event from the record-breaking events that have been observed so far $[13,15]$. Sometimes two or more kinds of extreme events co-occur, for example if flooding causes landslides in a watershed previously denuded by fire. In ecology such multiple impacts are called compound disturbances [16]. Fat-tailed distributions tend to magnify the correlations of extreme events and thereby increase the probability of compound disturbances [17].

In addition to these statistical challenges of anticipating extreme events, there are cognitive biases that can lead to irrational decisions when the stakes are high and probabilities are near zero or one $[18,19]$. For example a 'tyranny of recent events' (availability heuristic, [20]) causes people to misjudge risk, as when fears of terrorism are exaggerated for a time after a terrorist attack [21]. In contrast, when risks are familiar there is a tendency to underestimate the danger and overestimate one's ability to control the situation [21,22]. Sometimes inconsistent decisions are made about gains versus losses [18]. Different preferences for gains or losses of similar magnitude are the subject of prospect theory [23]. Perceiving gains and losses differently is a 'bias' in the context of rational choice theory, but not if prospect theory is instead used as the benchmark for expected behavior. Nonetheless, with respect to rational choice theory people can make poor decisions about risk of extreme events. People in isolation have their limits; collectively, however, people can create an institution to improve on these cognitive limits to rational behavior. The challenge is to design institutions so that the aggregate decision creates more good outcomes for the group. These (and other) behavioral phenomena inevitably affect societal decision making about extreme environmental events [24].

These interactions between complex aspects of natural systems and human cognition add to the challenges of understanding and managing extreme events, and make general resilience important. General resilience should protect social-ecological systems against vagaries of human volition as well as uncertainty about the relevant probabilities. In the remainder of the paper we discuss characteristics of institutions that contribute to general resilience of social-ecological systems.

\section{General Resilience as a Strategy}

Extreme events, including record-breaking extremes and new kinds of shocks, have been with us forever and may intensify in the future. General resilience - the capacity of social-ecological systems to adapt or transform in response to unfamiliar or unknown shocks - is essential for sustainability in the face of extreme events. However, the wide-ranging nature of general resilience makes it difficult to define specific steps for creating it. Instead it is possible to identify conditions that can enable or support the development of general resilience (Table 1). 
Diversity provides for different kinds of processes within a social-ecological system (functional diversity). It also provides for components that have similar functions but different responses to disturbance (response diversity), so the function is maintained even if one component is damaged. When teams of people are solving complex problems, diversity of perspectives and experience matters as much as individual ability [25]. The cumulative adverse effects of factors that diminish human wellbeing may also reduce the capacity of a society to respond effectively to disasters. There is a strong relationship between various aspects of human well-being and income inequality [26], suggesting that high income inequality reduces the general resilience of a society.

Modularity helps contain disturbances by compartmentalizing social-ecological systems [27]. For example, land management with prescribed fire uses firebreaks to limit the spread of the fire. This makes it possible to manage burn units independently, and thereby build landscape diversity. Similarly, quarantine mechanisms may restrict the spread of epidemics or invasive species. Modularity relates to the connectivity of a system, whereas diversity relates to the variety among elements of the system.

Openness of a social-ecological system is related to modularity at larger scales. Free trade among social-ecological systems often improves human well-being, for example. In ecosystems, seed dispersal plays a key role in recovery from large infrequent disturbances [28]. On the other hand, too much openness can transmit harmful shocks, as when bank collapses spread from country to country or an invasive species moves easily across a rather homogeneous and connected landscape. Tradeoffs between modularity and openness with respect to system fragility are understood for some ecosystems [27,29], and ecological principles have been applied to banking networks [30]. However the analysis of modularity versus openness is a research frontier for social-ecological systems.

Reserves - of organisms, knowledge, or skills for example - also contribute to recovery from disturbance. Residual plants and animals are important in ecological recovery from disturbance, even in extraordinarily devastating fires and volcanic eruptions [31]. Social memory and residual social networks play somewhat similar roles in recovery of social systems after major disasters [2].

Feedbacks in social-ecological systems are sometimes manageable, at least in part. Where it is possible, feedbacks should be managed to move the social-ecological system away from thresholds that trigger harmful outcomes. For example, reductions in soil phosphorus content move watersheds farther away from the threshold that causes toxic algae blooms and fish mortality in lakes and reservoirs [32]. In social-ecological systems, incentives or sanctions to conserve common-property resource stocks should be transparent, effective, and tied closely to the human actions that affect the resource, but implementation of such practices is not easy [33,34].

Nestedness of social-ecological systems enables polycentric governance [35]. This allows management systems to be scaled appropriately for the problems they are aiming to solve, capitalizing on the advantages of a particular governance arrangement while simultaneously having institutional backup systems [36]. Polycentric governance among global actors is now emerging as a response to shocks and new cross-scale connections. For example, interactions among climate change, ocean acidification, and marine biodiversity are addressed by the Global Partnership on Climate, Fisheries and Aquaculture (PaCFA) initiative. PaCFA currently includes representatives from FAO, UNEP, WorldFish, The World Bank's Profish Programme and 13 additional international organizations. The program involves deliberate attempts for mutual adjustments and self-organized action, with 
mechanisms ranging from information sharing to coordinated action and conflict resolution. PaCFA operates at the international level through the interplay of individuals, international organizations and their collaboration patterns [37].

Monitoring - the provision of transparent, relevant information about status and trends of the socialecological system - is essential for building and maintaining resilience. Indicators of social processes and the ecosystem help users and managers understand status and trends of critical ecosystem services. Sometimes indicators may provide early warnings of approaching thresholds [38,39].

Leadership and trust confer resilience on social-ecological systems and social relations in general. Often a mere handful of key individuals (e.g. institutional entrepreneurs that manage the context, complex as it is), help shape management and governance trajectories, developing shared visions, building trust, connecting social networks across levels, and seizing windows of opportunity for social-ecological transformations towards adaptive governance that nurture general resilience [40,41]. Nonetheless, resilience can be undermined by social dilemmas such as the incentive to cheat on agreements. This tendency can be countered if trust is built up through repeated interactions among people [42]. This aspect of trust construction plays a role in self-organizing regulation of environmental commons [33]. Trust is a component of social capital that sometimes helps to overcome such social dilemmas $[43,44]$.

Table 1. Enabling conditions for general resilience [1,27,45].

\begin{tabular}{|c|c|c|}
\hline System Property & Elements or Examples & Questions \\
\hline Diversity & $\begin{array}{l}\text { Species, functional, and response diversity } \\
\text { Cultural diversity } \\
\text { Heterogeneity of social-ecological system types on the } \\
\text { landscape or seascape }\end{array}$ & $\begin{array}{l}\text { Can multiple elements of the system perform } \\
\text { similar functions if one element is knocked out? } \\
\text { Can different elements of the system respond in } \\
\text { different ways to shocks? }\end{array}$ \\
\hline Modularity & $\begin{array}{l}\text { Quarantine mechanisms for pathogens or invasive species } \\
\text { People with different approaches to problem-solving } \\
\text { Independent organizations with similar functions in society }\end{array}$ & $\begin{array}{l}\text { Are subsets of the system insulated so that } \\
\text { shocks cannot spread? } \\
\text { Does the insulation prevent spread of ideas or } \\
\text { technologies? }\end{array}$ \\
\hline Openness & $\begin{array}{l}\text { Strength of connection between a social-ecological system } \\
\text { and neighboring social-ecological systems }\end{array}$ & $\begin{array}{l}\text { Can the social-ecological system maintain free } \\
\text { trade with neighboring systems? } \\
\text { Can the social-ecological system muffle shocks } \\
\text { that originate outside the system? } \\
\text { Is there an optimal solution to the tradeoff of } \\
\text { openness and modularity? }\end{array}$ \\
\hline Reserves & $\begin{array}{l}\text { Capacities to re-mobilize features of the system that have } \\
\text { been lost to disturbance, such as seed banks, recolonization } \\
\text { from neighboring systems, or social memory. }\end{array}$ & $\begin{array}{l}\text { Can key components of the social-ecological } \\
\text { system be regenerated? }\end{array}$ \\
\hline Feedbacks & $\begin{array}{l}\text { Nutrient cycles and over- or under-enrichment of ecosystems } \\
\text { Networks of economic transactions } \\
\text { Consequences of decisions }\end{array}$ & $\begin{array}{l}\text { Are control variables linked directly and } \\
\text { effectively to response variables? } \\
\text { Are sanctions and incentives tightly connected } \\
\text { to human actions? }\end{array}$ \\
\hline Nestedness & $\begin{array}{l}\text { Subwatersheds within watersheds } \\
\text { Township, County, Province, National, Global interacting } \\
\text { levels of governance systems }\end{array}$ & $\begin{array}{l}\text { Can the societal response to an opportunity or } \\
\text { problem be tuned to the natural scale? }\end{array}$ \\
\hline
\end{tabular}


Table 1. Cont.

\begin{tabular}{lll}
\hline System Property & Elements or Examples & Questions \\
\hline Monitoring & $\begin{array}{l}\text { Regular, transparent, and shared measurements of } \\
\text { social-ecological variables }\end{array}$ & $\begin{array}{l}\text { How much do people know about the status and } \\
\text { trends of the system that supports their lives, } \\
\text { livelihoods and society? }\end{array}$ \\
\hline Leadership & Recognition of barriers and bridges that could change & Can the society frame problems for effective \\
& $\begin{array}{l}\text { resilience } \\
\text { Building networks }\end{array}$ & action in complex social-ecological contexts? \\
& Development of trust in repeated interactions & Can people collaborate effectively in relation to \\
\end{tabular}

\section{Fostering General Resilience}

General resilience is the area of research currently receiving most attention from those involved in applying resilience in practice. Resilience assessments have tended to focus on aspects of the specified resilience of a particular region. The principles for enhancing resilience of individual social-ecological systems $[1,5,45]$ are consistent with the types of enabling conditions for general resilience just described. For example, Biggs et al. [45] suggest seven principles for enhancing resilience, which address diversity, connectivity, feedbacks and slow variables, polycentric governance, learning and experimentation, breadth of participation, and the complex adaptive characteristics of social-ecological systems. In this section of the paper, we touch upon some general-resilience implications of recent studies in other literatures, including those on natural disasters, social vulnerability, scenario planning, and adaptive management.

Some elements of general resilience are implicit in the literature of natural disasters. A recent report from the World Bank [46] focused on four policy needs for managing environmental disasters: (1) make information about environmental disaster risk more easily accessible; (2) use land and housing markets to induce people to locate in appropriate areas and take preventive measures; (3) provide adequate infrastructure and public services to reduce vulnerabilities; and (4) build institutions that permit public oversight of disaster preparedness and disaster response. These are important practical steps at the level of national governance. Consideration of general resilience reminds us that additional factors must be considered, such as polycentric governance to match scales of problems and solutions.

After a disaster occurs, rapid response is crucial but it is also important to rebuild resilience, as detailed in a recent meeting of disaster experts [47]. Disturbance erodes capacity to organize and respond, and induces new feedbacks that tend to keep the system in the disturbed state. The longer a community stays in a disturbed state after a disaster the more difficult recovery becomes, and eventually it may not be able to recover at all. Yet quick-fix responses may lead to superficial outcomes that are harmful in the long run [48]. Thus response strategies for disasters must also consider rebuilding of resilience against possible future disturbances.

The attributes that confer social-ecological resilience to shocks are often unrecognized, and they may be eroded or lost over time unless they are actively fostered and managed [49]. Increased awareness, learning and collaboration across sectors [50,51], improved education, 
mobilization of experience and social capital, leadership, and multi-scale governance are critical elements in reducing vulnerability and building resilience to shocks [2,50,52]. All of these factors affect social vulnerabilities. Failure to reduce social vulnerabilities can amplify risk more than the escalation of physical hazards does [46].

Scenario planning is a method of exploring the resilience of a social-ecological system to a wide range of factors. Scenarios are a coordinated set of stories that reveal sharply different alternative futures for a social-ecological system. The alternate scenarios within a set diverge as a result of human decisions, diverging drivers, and large-consequence events. The purpose of the set of scenarios is to evoke conversations about thresholds that separate different future pathways of a social-ecological system. The alternative pathways often have different implications for resilience to future shocks that are outside the scope of the scenarios. For example, the Millennium Ecosystem Assessment [51] described four different states of the world in 2050. Each state has different resilience to climate changes that are expected to unfold after 2050. In regional environmental assessment and planning, the scenario process has many similarities to adaptive ecosystem management [53], a pioneering form of resilience analysis.

Adaptive management is always embedded in institutions and governance systems. Extreme events call for governance systems that provide incentives for resilience building and are themselves resilient to such events [54]. Adaptive governance systems with polycentric arrangements and bridging organizations connecting scales enable adaptive management [45,55]. For general resilience such attributes should not be subject to planning and control in a narrowly prescribed way [33], but instead supported by enabling legislation and economic incentives that allow for self-regulation and innovation. Critical features of wellfunctioning adaptive governance systems for social-ecological resilience include the role of key actors, bridging organizations, flexible institutions, and social networks that serve to connect the dynamic responses and strategies [56,57].

\section{Conclusion}

General resilience has a valuable role in managing rare extreme events with large consequences for social ecological systems. Of necessity, the guidelines for general resilience are rather non-specific. Nonetheless, in applications of general resilience it is essential to tailor policies and practices to the particular characteristics (governance, social interactions, ecosystem processes, etc.) of the social-ecological system that is being managed. In some cases, actions to build resilience against specific extreme events also contribute to general resilience.

The greatest challenge of general resilience is to design and implement concrete policies and actions. Unless incentives are constructed properly, short-term decision making will tend away from the longterm view that is needed to build and maintain general resilience. How can long-term practices be woven into actions that also meet the immediate needs of people and ecosystems? This is the crucial challenge of general resilience, a challenge that faces many real limits of costs and political barriers. General resilience is a public good that has a cost. How much resilience is needed, in what dimensions, and at what cost? Policies for general resilience must overcome budget limitations, address trade-offs, be acceptable to competing interests, and overcome barriers in politics and the structure of existing agencies and institutions. It may well be the case that costs are too great to justify more investment in 
general resilience. Such practical limitations may be the greatest barrier to policies for general resilience.

Research and practice have built some insight about how to build general resilience. Nonetheless, much research is needed to understand practices for general resilience in diverse situations. For example, how general is general resilience? Are certain characteristics of social-ecological systems (Table 1) more or less effective for building general resilience? Are some characteristics particularly well suited to building resilience for certain classes of social-ecological problems? So far there are only a few case studies that reveal long-run effectiveness of strategies for general resilience. Further research on general resilience is a high priority, in view of the rapid rates of change and emergence of new interactions and feedback in social-ecological systems.

\section{Acknowledgments}

This paper derived from the 2010 Askö Workshop of the Beijer Institute of Ecological Economics. Financial support was provided by the Kjell and Märta Beijer Foundation, Formas and by Mistra through a core grant to the Stockholm Resilience Centre, a cross-faculty research centre at Stockholm University. SRC acknowledges support of NSF.

\section{Conflict of Interest}

The authors declare no conflict of interest.

\section{References}

1. Walker, B.; Salt, D. Resilience Practice; Island Press: Washington, DC, USA, 2012.

2. Adger, W.N.; Hughes, T.P.; Folke, C.; Carpenter, S.R.; Rockström, J. Social-ecological resilience to coastal disasters. Science 2005, 309, 1036-1039.

3. Adger, W.N. Vulnerability. Global Environ.Change 2006, 16, 268-281.

4. World Economic Forum. Building Resilience to Natural Disasters: A Framework for Private Sector Engagement; World Economic Forum: Geneva, Switzerland, 2008.

5. Walker, B.; Salt, D. Resilience Thinking; Island Press: Washington, DC, USA, 2006.

6. d'Aignaux, J.N.H.; Cousens, S.N.; Smith, P.G. Predictability of the UK variant Creutzfeldt-Jakob disease epidemic. Science 2001, 294, 1729-1731.

7. Normile, D. Scientific consensus on great quake came too late. Science 2011, 332, 22-23.

8. Cutter, S.L.; Emrich, C. Are natural hazards and disaster losses in the U.S. increasing? Eos 2005, $86,381-396$.

9. Emanuel, K. Increasing destructiveness of tropical cyclones over the past 30 years. Nature 2005, 436, 686-688.

10. Meehl, G.A.; Tebaldi, C.; Walton, G.; Easterling, D.; McDaniel, L. Relative increase of record high maximum temperatures compared to record low minimum temperatures in the U.S. Geophys. Res. Lett. 2009, 36, L23701.

11. Trenberth, K.E.; Fasullo, J.T. Climate extremes and climate change: The Russian heat wave and other climate extremes of 2010. J. Geophys. Res. 2012, 117, D17103. 
12. Webster, P.J.; Holland, G.J.; Curry, J.A.; Chang, H.-R. Changes in tropical cyclone number, duration, and intensity in a warming environment. Science 2005, 309, 1844-1846.

13. Embrechts, P.; Kluppelberg, P.; Mikosch, T. Modeling Extremal Events for Insurance and Finance; Springer-Verlag: Berlin, Germany, 1997.

14. Malamud, B.D. Tails of natural hazards. Physics World 2004, 17, 31-35.

15. Kousky, C.; Cooke, R. Adapting to Extreme Events: Managing Fat Tails; Resources for the Future: Washington, DC, USA, 2010.

16. Paine, R.T.; Tegner, M.J.; Johnson, E.A. Compounded perturbations yield ecological surprises. Ecosystems 1998, 1, 535-545.

17. Embrechts, P.; McNeil, A.; Straumann, D. Correlation and Dependence in Risk Management: Properties and Pitfalls. In Risk Management: Value at Risk and Beyond; Dempster, M., Ed.; Cambridge University Press: Cambridge, UK, 2002; pp. 176-223.

18. Kahneman, D. Thinking, Fast and Slow; Farrar, Straus and Giroux: New York, USA, 2011.

19. Kahneman, D. Maps of bounded rationality: Psychology for behavioral economics. Am. Econ. Rev. 2003, 93, 1449-1475.

20. Tversky, A.; Kahneman, D. Availability: A heuristic for judging frequency and probability. Cognit. Psychol. 1973, 4, 207-232.

21. Sunstein, C.R. Risk and Reason; Cambridge University Press: Cambridge, UK, 2002.

22. Thaler, R.; Sunstein, C.R. Nudge: Improving Decisions About Health, Wealth, and Happiness; Yale University Press: New Haven, Connecticut, USA, 2008.

23. Tversky, A.; Kahneman, D. The framing of decisions and the psychology of choice. Science 1981, 211, 453-458.

24. Shogren, J.; Taylor, L. On behavioral environmental economics. Rev. Environ. Econ. Pol. 2007, 2, 26-44.

25. Page, S.E. The Difference; Princeton University Press: Princeton, NJ, USA, 2007; p. 424.

26. Wilkinson, R.G.; Pickett, K. The Spirit Level; Allen Lane: London, UK, 2009.

27. Levin, S.A. Fragile Dominion; Perseus: New York, USA, 1999.

28. Turner, M.G.; Baker, W.L.; Peterson, C.J.; Peet, R.K. Factors influencing succession: Lessons from large, infrequent natural disturbances. Ecosystems 1998, 1, 511-523.

29. Scheffer, M.; Carpenter, S.R.; Lenton, T.M.; Bascompte, J.; Brock, W.; Dakos, V.; van de Koppel, J.; van de Leemput, I.A.; Levin, S.A.; van Nes, E.H.; Pascual, M.; Vandermeer, J. Anticipating critical transitions. Science 2012, 338, 344-348.

30. May, R.M.; Levin, S.A.; Sugihara, G. Complex systems: Ecology for bankers. Nature 2008, 451, 893-895.

31. Turner, M.G. Disturbance and landscape dynamics in a changing world. Ecology 2010, 91, 2833-2849.

32. Carpenter, S.R. Eutrophication of aquatic ecosystems: Bistability and soil phosphorus. PNAS 2005, 102, 10002-10005.

33. Ostrom, E. A diagnostic approach for going beyond panaceas. PNAS 2007, 104, 15181-15187.

34. Ostrom, E. A general framework for analyzing sustainability of social-ecological systems. Science 2009, 325, 419-422. 
35. Ostrom, E. Polycentric systems for coping with collective action and global environmental change. Global Environ. Change 2010, 20, 550-557.

36. Andersson, K.; Ostrom, E. Analyzing decentralized resource regimes from a polycentric perspective. Pol. Sci. 2008, 41, 71-93.

37. Galaz, V.; Crona, B.; Österblom, H.; Olsson, P.; Folke, C. Polycentric systems and interacting planetary boundaries-Emerging governance of climate change-ocean acidification-marine biodiversity. Ecol. Econ. 2012, 81, 21-32.

38. Scheffer, M.; Bascompte, J.; Brock, W.A.; Brovkin, V.; Carpenter, S.R.; Dakos, V.; Held, H.; van Nes, E.H.; Rietkerk, M.; Sugihara, G. Early-warning signals for critical transitions. Nature 2009, 461, 53-59.

39. Carpenter, S.R.; Cole, J.J.; Pace, M.L.; Batt, R.; Brock, W.A.; Cline, T.; Coloso, J.; Hodgson, J.R.; Kitchell, J.F.; Seekell, D.A.; Smith, L.; Weidel, B. Early warnings of regime shifts: A whole-ecosystem experiment. Science 2011, 332, 1079-1082.

40. Olsson, P.; Folke, C.; Hughes, T.P. Navigating the transition to ecosystem-based management of the Great Barrier Reef, Australia. PNAS 2008, 105, 9489-9494.

41. Moore, M.-L.; Westley, F. Surmountable chasms: Networks and social innovation for resilient systems. Ecol. Soc. 2011, 16, 1.

42. Glaeser, E.L.; Laibson, D.I.; Scheinkman, J.A.; Soutter, C.L. Measuring trust. Q. J. Econ. 2000, $115,811-846$.

43. Rothstein, B. Social Traps and the Problem of Trust; Cambridge University Press: Cambridge, UK, 2005.

44. Tomkins, C. Interdependencies, trust and information in relationships, alliances and networks. Account. Org. Soc. 2001, 26, 161-191.

45. Biggs, R.; Schlüter, M.; Biggs, D.; Bohensky, E.L.; BurnSilver, S.; Cundill, G.; Dakos, V.; Daw, T.M.; Evans, L.S.; Kotschy, K.; et al. Toward principles for enhancing the resilience of ecosystem services. Annu. Rev. Environ. Resour. 2012, 37, 421-448.

46. WorldBank. Natural Hazards, UnNatural Disasters; The International Bank for Reconstruction and Development, The World Bank: Washington, DC, USA, 2010.

47. Walker, B.; Westley, F. Perspectives on resilience to disasters across sectors and cultures. Ecol. Soc. 2011, 16, 2.

48. Sterner, T.; Troell, M.; Vincent, J.; Aniyar, S.; Barrett, S.; Brock, W.; Carpenter, S.; Chopra, K.; Ehrlich, P.; Hoel, M.; et al. Quick fixes for the environment: Part of the solution or part of the problem? Environment: Science and Policy for Sustainable Development 2006, 48, 20-27.

49. Boyd, E.; Folke, C. Adapting Institutions: Governance, Complexity and Social-Ecological Resilience; Cambridge University Press: Cambridge, UK, 2012.

50. Tompkins, E.L.; Hurlston, L.-A. Public-Private Partnership in the Provision of Environmental Governance: A Case of Disaster Management. In Adapting Institutions: Governance, Complexity and Social-Ecological Resilience; Boyd, E., Folke, C., Eds.; Cambridge University Press: Cambridge, UK, 2012.

51. Millennium Ecosystem Assessment. Ecosystems and Human Wellbeing: Scenarios; Island Press: Washington, DC, USA, 2005. 
52. McSweeney, K.; Coomes, O.T. Climate-related disaster opens a window of opportunity for rural poor in northeastern Honduras. PNAS 2011, 108, 5203-5208.

53. Peterson, G.D.; Cumming, G.S.; Carpenter, S.R. Scenario planning: A tool for conservation in an uncertain world. Conserv. Biol. 2003, 17, 358-366.

54. Folke, C.; Hahn, T.; Olsson, P.; Norberg, J. Adaptive governance of social-ecological systems. Annu. Rev. Environ. Resour. 2005, 30, 441-473.

55. Crona, B.I.; Parker, J.N. Learning in support of governance: Theories, methods, and a framework to assess how bridging organizations contribute to adaptive resource governance. Ecol. Soc. 2012, $17,4$.

56. Olsson, P.; Gunderson, L.H.; Carpenter, S.R.; Ryan, P.; Lebel, L.; Folke, C.; Holling, C.S. Shooting the rapids: Navigating transitions to adaptive governance of social-ecological systems. Ecol. Soc. 2006, 11, 18.

57. Österblom, H.; Bodin, Ö. Global cooperation among diverse organizations to reduce illegal fishing in the Southern Ocean. Conserv Biol. 2012, 26, 638-648.

(C) 2012 by the authors; licensee MDPI, Basel, Switzerland. This article is an open access article distributed under the terms and conditions of the Creative Commons Attribution license (http://creativecommons.org/licenses/by/3.0/). 